\title{
Correction to: Clinical characteristics and thyroid hormone dynamics of thyrotropin-secreting pituitary adenomas at a single institution
}

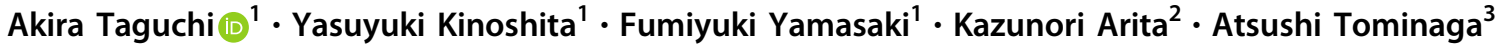

Published online: 20 February 2021

(c) Springer Science+Business Media, LLC, part of Springer Nature 2021

Correction to: Endocrine

https://doi.org/10.1007/s12020-020-02556-2
The original version of the article has a wrong Fig. 2a and it has been replaced with the new one.

The corrected Fig. 2a is given below:

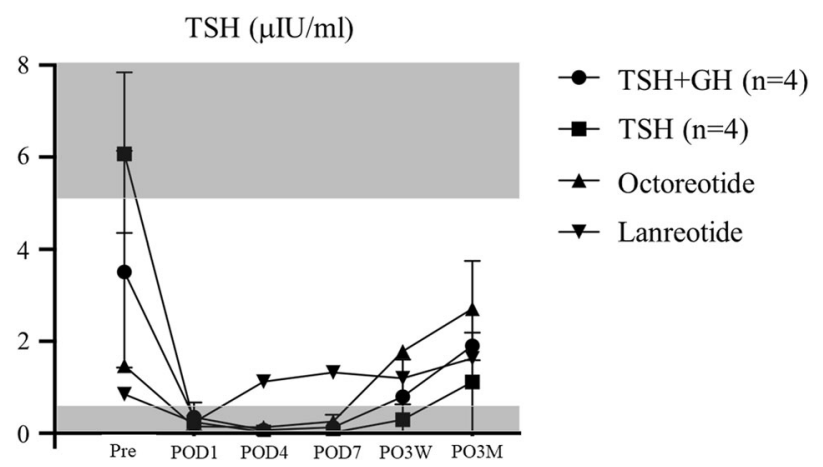

Fig. $2 a$
The original article can be found online at https://doi.org/10.1007/ s12020-020-02556-2.

$\triangle$ Akira Taguchi

akira.taguch.0929@gmail.com

1 Department of Neurosurgery, Graduate School of Biomedical and Health Sciences, Hiroshima University, 1-2-3, Kasumi, Minamiku, Hiroshima 734-8551, Japan

2 Department of Neurosurgery, Izumi Regional Medical Center, Izumi, Japan

3 Department of Neurosurgery and Neuro-Endovascular Therapy, Hiroshima Prefectural Hospital, Hiroshima, Japan 